\title{
Indoleamine 2,3-dioxygenase expression and overall survival in patients diagnosed with breast cancer in Pakistan
}

This article was published in the following Dove Medical Press journal: Cancer Management and Research

\author{
Kashif Asghar' \\ Asif Loya ${ }^{2}$ \\ Iftikhar Ali Rana ${ }^{2}$ \\ Muhammad Tahseen ${ }^{2}$ \\ Muhammad Ishaq ${ }^{2}$ \\ Asim Farooq ${ }^{3}$ \\ Muhammad Abu Bakar ${ }^{4}$ \\ Iqra Masood ${ }^{5}$ \\ 'Department of Basic Sciences, \\ Shaukat Khanum Memorial Cancer \\ Hospital and Research Centre \\ (SKMCH \& RC), Lahore, Pakistan; \\ ${ }^{2}$ Department of Pathology, Shaukat \\ Khanum Memorial Cancer Hospital \\ and Research Centre (SKMCH \& \\ RC), Lahore, Pakistan; ${ }^{3}$ Department \\ of Biomedical Engineering \& Sciences, \\ School of Mechanical \& Manufacturing \\ Engineering, National University \\ of Sciences \& Technology (NUST), \\ Islamabad, Pakistan; ${ }^{4}$ Department \\ of Cancer Registry and Clinical \\ Data Management, Shaukat Khanum \\ Memorial Cancer Hospital and \\ Research Centre (SKMCH \& RC), \\ Lahore, Pakistan; ${ }^{5}$ Department of \\ Clinical Research, Shaukat Khanum \\ Memorial Cancer Hospital and \\ Research Centre (SKMCH \& RC), \\ Lahore, Pakistan
}

Correspondence: Kashif Asghar Shaukat Khanum Memorial Cancer Hospital and Research Centre (SKMCH \& RC), 7-A Block R-3, Johar Town, Lahore, Pakistan

Tel +92 4235905000 ext4365

Fax +92 4235945206

Email kashifasghar@skm.org.pk
Background: Immune dysfunction in breast cancer patients is well established. Indoleamine 2,3-dioxygenase (IDO) is an immunosuppressive enzyme that is linked with progression of cancer. IDO is overexpressed in triple-negative breast cancer (TNBC) cases.

Materials and methods: We conducted the first study to analyze IDO expression and overall survival in breast cancer cases in Pakistan. Expression of IDO, estrogen receptor (ER), progesterone receptor (PR), and human EGF receptor 2 (HER2) was evaluated by immunohistochemistry. Formalin-fixed paraffin-embedded breast cancer tissues of 100 (TNBC, $n=49$ and non-TNBC, $\mathrm{n}=51$ ) patients were obtained from Shaukat Khanum Memorial Cancer Hospital and Research Centre. IDO expression was analyzed in association with clinicopathological features and overall survival. A total of 100 patients were classified based on the ordinal IDO score variables as low, medium, and high. In addition, overall mean age and SD of patients was 48.28 \pm 11.82 .

Results: Immunohistochemical analysis showed that high IDO was observed in the TNBC patients $(65.3 \%)$ compared to that in the non-TNBC patients $(33.3 \%)$. Multivariable analyses showed that TNBC was an independent risk factor for high IDO expression. Overall survival was also significantly associated with IDO score.

Conclusion: Our study showed that IDO protein expression is higher in TNBC patients $(P<0.01)$ and may suggest its role in disease pathogenesis. TNBC might be effectively treated with IDO inhibitors. Furthermore, high IDO expression is considerably associated with overall decreased patient survival. IDO might be utilized as a potential biomarker and immunotherapeutic target in breast cancer patients.

Keywords: indoleamine 2, 3-dioxygenase, breast cancer, triple-negative breast cancer, Pakistan

\section{Introduction}

Indoleamine 2,3-dioxygenase (IDO) is an immunosuppressive enzyme that catabolizes L-tryptophan into kynurenines. ${ }^{1,2}$ Deficiency of tryptophan hinders the cytotoxicity of T cells. ${ }^{3}$ The metabolites generated from tryptophan metabolism activate T cell apoptosis in vitro. ${ }^{4}$ IDO is involved in inhibition of T-cell immune responses through induction of regulatory $\mathrm{T}$ cell (T-reg) differentiation. ${ }^{5}$ IDO is implicated in tumor immune-escape mechanisms. ${ }^{4,6,7}$ IDO overexpression results in immunosuppression and immunotolerance. ${ }^{7}$ IDO-expressing dendritic cells (DCs) are found in tissues and draining lymph nodes of patients with breast cancer. ${ }^{8}$ IDO emerged from tumor has capability to obstruct the antitumor immune responses and promote metastasis. ${ }^{9,10}$ Several researchers identified the IDO expression in breast, colorectal, ovarian, and endometrial cancers. ${ }^{11-14}$ IDO inhibition is an evolving antitumor 
approach in the field of cancer immunotherapeutic. Currently, several IDO inhibitors are the part of clinical trials. ${ }^{15}$

Breast cancer affects majority of the Pakistani women, accounting for $40.2 \%$ of all female malignancies. ${ }^{16} \mathrm{~A}$ study conducted by $\mathrm{Yu}$ et $\mathrm{l}^{17}$ established that high IDO expression in breast cancer patients was linked with the involvement of lymph node and a worse recurrence-free survival. Triple-negative breast cancer (TNBC) is characterized by the absence of immunohistochemical expression of estrogen receptor (ER), progesterone receptor (PR), and human EGF receptor 2 (HER2). ${ }^{18}$ TNBC is approximately accounted for $15 \%-20 \%$ of all breast cancers. ${ }^{18,19}$ Due to advancement in the field of cancer research and management, the overall survival of breast cancer patients has been improved. However, TNBC is an aggressive tumor compared to other breast cancers, and therapeutic treatment options are limited. ${ }^{19}$ Overall survival of patients with advanced TNBC is less than a year. Therefore, identification of precise targets and novel therapies for TNBC patients remains a major challenge. ${ }^{20}$ Jaquemiere et $\mathrm{al}^{21}$ established that IDO was overexpressed at transcriptional and translational level in a subset of TNBC. Currently, no data are available regarding IDO expression in TNBC patients in Pakistan. The current study was conducted in Pakistan to analyze the IDO expression in relation with overall survival in breast cancer patients.

\section{Materials and methods}

\section{Specimen collection and survival data}

Formalin-fixed paraffin-embedded tumor specimens were retrieved from 100 breast cancer patients for retrospective analysis from pathology department at Shaukat Khanum Memorial Cancer Hospital and Research Centre (SKMCH \& RC) Lahore, Pakistan (It is the only charitable cancer hospital in the world where approximately $75 \%$ of cancer patients are treated completely free of charge). All patients were diagnosed between 2007 and 2009 with breast cancer. They had no history of breast cancer. All the patients selected for the current study were treatment naive. Nottingham Histologic Score system was used for tumor grading. The expression of ER, PR, and HER2 was investigated through immunohistochemistry by using standard methods. ${ }^{22}$ The information about the clinicopathological characteristics of the breast cancer patients was acquired from pathology reports of hospital medical record system.

Survival data were collected from the electronic hospital information system (eHIS) of SKMCH \& RC (date of search, May 30, 2018) for 100 patients. The current study consisted of retrospective arm and was approved by the institutional review board (IRB; study IRB-16-08) of SKMCH \& RC.
The waiver for informed consent was granted for this study by IRB (SKMCH \& RC), which is in accordance with the Declaration of Helsinki. We used the specimens that were available at SKMCH \& RC. The information recorded by the group was in such a manner that the subjects could not be identified. Information was retrieved form the physician notes only. The research involves no procedures for which informed consent is normally required outside of the research context. The IRB review process of SKMCH \& $\mathrm{RC}$ is in compliance with the International Council for Harmonisation of Technical Requirements for Pharmaceuticals for Human Use- Good Clinical Practice Guidelines.

\section{Immunohistochemical staining and scoring of IDO}

Slides were stained using a Bond III Leica automated system (Leica Biosystems Melbourne, Australia) as per manufacturer's protocol. Slides were deparaffinized with Bond Dewax solution (\#AR922; Leica Microsystems). Heat-induced epitope retrieval method was used on the automated system with Bond ER-2 (\#AR9640; Leica Microsystems) for 20 minutes. The primary antibody IDO1 (Abcam, Cambridge, United Kingdom; \# ab55305, anti-indoleamine 2,3-dioxygenase antibody) was used at a 1:200 concentration in primary antibody diluent Bond (\#AR 9352) and incubated for 5 minutes. IDO labeling was visualized using Bond ${ }^{\mathrm{TM}}$ polymer refine detection kit (\#DS9800 Leica Biosystems Newcastle Upon Tyne, United Kingdom). Slides were incubated with peroxide block (hydrogen peroxide) for 5 minutes and then incubated with post-primary rabbit antimouse IgG for 8 minutes. Then, further, slides were incubated with polymer anti-rabbit poly-horseradish peroxidase (HRP)IgG for 8 minutes. 3, 3'-diaminobenzidine (DAB) was applied for 10 minutes. At each step, washing was performed with Bond wash buffer (\#AR 9590). Slides were counterstained with hematoxylin for 5 minutes. Slides were visualized by an optical microscope (Provis AX-70; Olympus, Melville, NY, USA).

The slides were numerically scored by pathologists. It was a blind histopathologic evaluation. Two factors were considered for IDO staining, i.e., percent cells staining positive $(0=0 \%, 1=1 \%-33 \%, 2=34-66 \%$, and $3 \geq 66 \%)$ and intensity of cytoplasmic staining $(0,1,2$, and 3$)$. The percentages of positive staining of cells and cytoplasmic staining values were combined to get the final IDO score. The scores were further classified as low $=1-3$, medium $=4-6$, and high=7-9.

\section{Statistical analyses}

Statistical analyses were performed using SPSS software (version 20.0; IBM Corporation, Armonk, NY, USA). Per- 
centages (proportions) were used for categorical variables, while mean and SD was used for continuous variables. Bivariate analysis was done using chi-squared or Fisher's exact tests (when necessary). For continuous explanatory variable such as age, independent $t$-test was performed. Univariable and multivariable ordinal logistic regression model was used to find the risk factors. The Kaplan-Meier method was used to estimate overall survival. Survival differences were scrutinized by the Breslow (Generalized Wilcoxon) test. Statistical significance was defined as a two-tailed $P$-value 0.05 .

\section{Results}

\section{Demographic and patient characteristics}

The baseline characteristics of breast cancer patients $(n=100)$ are outlined in Table 1 . The overall mean age at diagnosis of breast cancer was $48.28 \pm 11.82$ years (range, 23-75 years), and all the patients were female. Based on the ethnicity, most patients were from Punjabi background (87\%). According to the TNM classification system, 10.9\% tumors were $\mathrm{T} 1$ and $89.1 \%$ tumors were $\mathrm{T} 2 / \mathrm{T} 3$. The grade distribution was I, II and III respectively. $61.5 \%$ tumors were presenting grade III. The patients' positive for node and metastasis were $57.5 \%$ and $56.3 \%$, respectively. The frequency for ER, PR, and HER2-neu positive was $31.0 \%$, $26.0 \%$, and $26.0 \%$, respectively. There was a statistical association between IDO scoring and TNBC $(P=0.003)$. Our data revealed that $35 \%$ patients died approximately after 24-91 months of breast cancer diagnosis, 15\% patients were lost to follow-up, and $50 \%$ patients are still alive.

\section{Survival data analysis}

Overall survival was compared among the IDO low, IDO medium, and IDO high groups. There was a statistically significant difference $(P=0.04)$ between the three groups as shown in Figure 1. The survival time in IDO scores was highest in low expression category ( $91 \pm 41.9$ months) compared to that in medium and high expression categories $(50 \pm 4.4$ and $24 \pm 10.1$ months, respectively). The overall median

Table I Patients and tumor characteristics by low, medium, and high IDO scores

\begin{tabular}{|c|c|c|c|c|c|c|}
\hline Variables & Characteristics & $\begin{array}{l}\text { Total, } \mathbf{n} \\
\text { (\%) }\end{array}$ & $\begin{array}{l}\text { Low IDO } \\
\text { score, } 24 \\
(24.0 \%)\end{array}$ & $\begin{array}{l}\text { Medium } \\
\text { IDO score, } \\
27(27.0 \%)\end{array}$ & \begin{tabular}{|l} 
High IDO \\
score, 49 \\
$(49.0 \%)$
\end{tabular} & $P$-value \\
\hline Age (years), mean $\pm S D$ & & $48.28 \pm 11.82$ & $48.04 \pm 11.03$ & $46.07 \pm 11.26$ & $49.61 \pm 12.53$ & 0.46 \\
\hline \multirow[t]{3}{*}{ Grade, n (\%) } & II & $35(38.5)$ & $10(28.6)$ & $10(28.6)$ & $15(42.9)$ & 0.32 \\
\hline & III & $56(6 I .5)$ & $12(2 \mathrm{I} .4)$ & II (19.6) & $33(58.9)$ & \\
\hline & Total & $91(100.0)$ & $22(24.2)$ & $21(23.1)$ & $48(52.7)$ & \\
\hline \multirow[t]{3}{*}{ Metastasis, n (\%) } & Negative & $38(43.7)$ & $10(26.3)$ & $7(18.4)$ & $21(55.3)$ & 0.31 \\
\hline & Positive & $49(56.3)$ & $12(24.5)$ & $16(32.7)$ & $21(42.9)$ & \\
\hline & Total & $87(100.0)$ & $22(25.3)$ & $23(26.4)$ & $42(48.3)$ & \\
\hline \multirow[t]{3}{*}{ Tumor size, $\mathrm{n}(\%)$} & TI & $7(10.9)$ & $3(42.9)$ & $\mathrm{I}(\mathrm{I} 4.3)$ & $3(42.9)$ & 0.69 \\
\hline & $\mathrm{T} 2 / \mathrm{T} 3$ & $57(89.1)$ & $15(26.3)$ & $17(29.8)$ & $25(43.9)$ & \\
\hline & Total & $64(100.0)$ & $18(28.1)$ & $18(28.1)$ & $28(43.8)$ & \\
\hline \multirow[t]{3}{*}{ Nodes, n (\%) } & Negative & $37(42.5)$ & $10(27.0)$ & $6(16.2)$ & $21(56.8)$ & 0.17 \\
\hline & Positive & $50(57.5)$ & $12(24.0)$ & $17(34.0)$ & $21(42.0)$ & \\
\hline & Total & $87(100.0)$ & $22(25.3)$ & $23(26.4)$ & $42(48.3)$ & \\
\hline \multirow[t]{3}{*}{ Estrogen receptor, n (\%) } & Negative & $69(69.0)$ & $15(21.7)$ & $16(23.2)$ & $38(55.1)$ & 0.20 \\
\hline & Positive & $31(31.0)$ & $9(29.0)$ & II (35.5) & II (35.5) & \\
\hline & Total & $100(100.0)$ & $24(24.0)$ & $27(27.0)$ & $49(49.0)$ & \\
\hline \multirow[t]{3}{*}{ Progesterone receptor, $\mathrm{n}(\%)$} & Negative & $74(84.0)$ & $18(24.3)$ & $17(23.0)$ & $39(52.7)$ & 0.28 \\
\hline & Positive & $26(26.0)$ & $6(23.1)$ & $10(38.5)$ & $10(38.5)$ & \\
\hline & Total & $100(100.0)$ & $24(24.0)$ & $27(27.0)$ & $49(49.0)$ & \\
\hline \multirow[t]{3}{*}{ HER2-neu receptor, n (\%) } & Negative & $74(84.0)$ & $17(23.0)$ & $19(25.7)$ & $38(5 I .4)$ & 0.73 \\
\hline & Positive & $26(26.0)$ & $7(26.9)$ & $8(30.8)$ & II (42.3) & \\
\hline & Total & $100(100.0)$ & $24(24.0)$ & $27(27.0)$ & $49(49.0)$ & \\
\hline \multirow{3}{*}{$\begin{array}{l}\text { Triple-negative breast cancer, } \\
\mathrm{n}(\%)\end{array}$} & No & $5 I(5 I .0)$ & $14(27.5)$ & $20(39.2)$ & $17(33.3)$ & $0.003^{\mathrm{a}}$ \\
\hline & Yes & $49(49.0)$ & $10(20.4)$ & $7(14.3)$ & $32(65.3)$ & \\
\hline & Total & $100(100.0)$ & $24(24.0)$ & $27(27.0)$ & $49(49.0)$ & \\
\hline
\end{tabular}

Note: aStatistical significance: $P<0.05$.

Abbreviations: HER2, human EGF receptor 2; IDO, indoleamine 2,3 dioxygenase. 


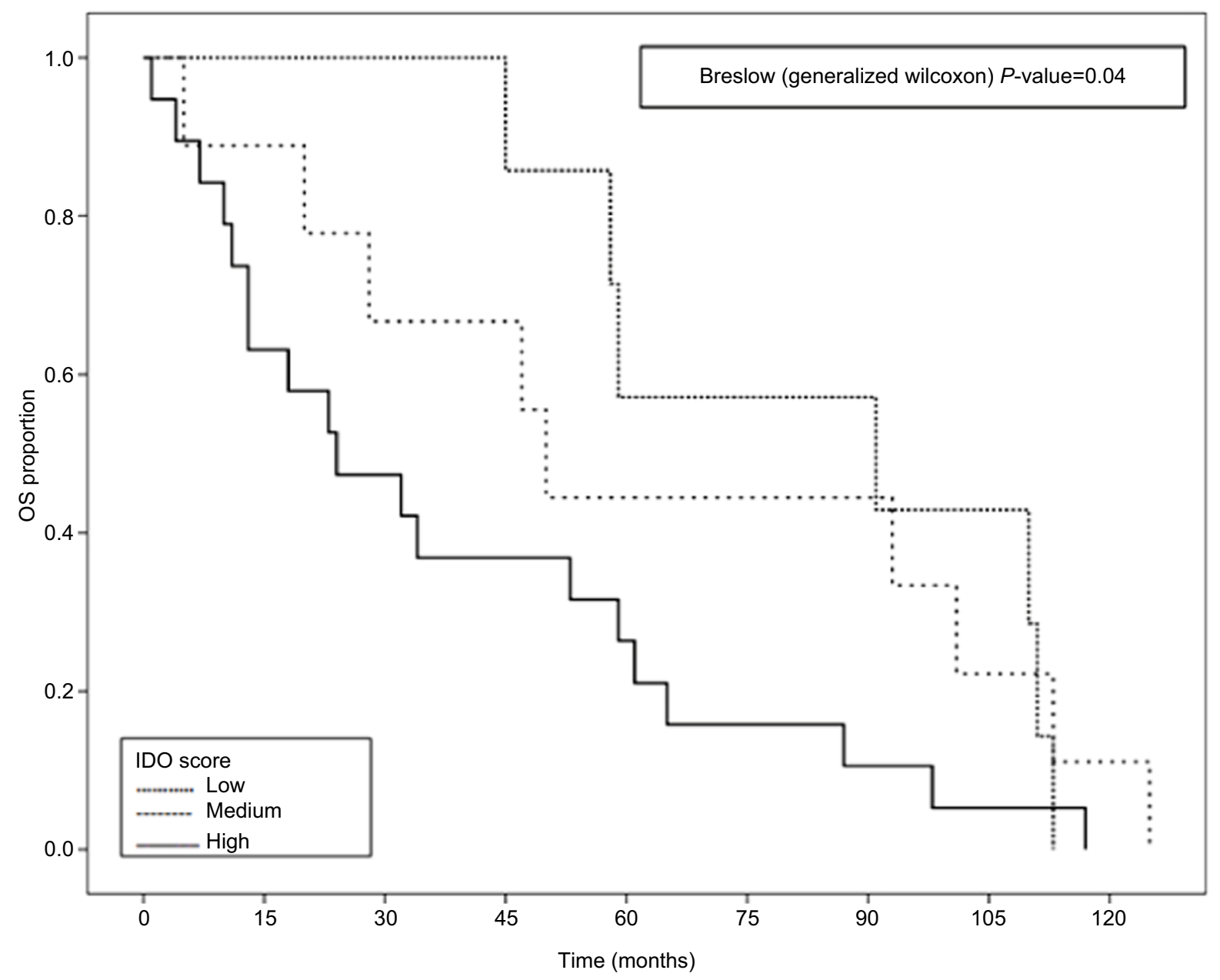

Figure I OS stratified by three groups of IDO scores.

Abbreviations: IDO, indoleamine 2,3 dioxygenase; OS, overall survival.

survival time for breast cancer patients with IDO score was $50 \pm 14.19$ months.

\section{IDO staining results}

To identify the IDO expression, we selected formalin-fixed paraffin-embedded 100 tumor specimens. All breast cancer specimens stained positive for IDO. The mean and SD value was 6.29 \pm 3.09 , median (range) was 6 (1-9), and mode was 9. Out of 100 samples, IDO high, IDO medium, and IDO low scores were $49 \%, 27 \%$, and $24 \%$, respectively (Figure 2). IDO immunostaining is shown in Figure 3. The staining was mostly cytoplasmic and detected in malignant ductal tumors and invasive ductal tumors cells.

\section{Univariable and multivariable analysis}

Table 2 summarizes various clinicopathological factors of patients, which were investigated in the univariable and multivariable statistical analyses to identify their association with IDO expression. In multivariable ordinal model, we did not observe an association between IDO

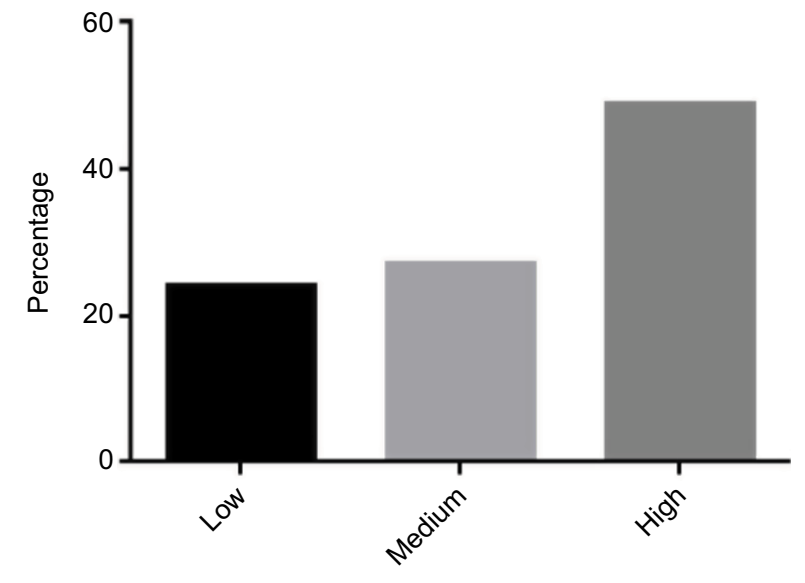

IDO expression

Figure 2 Histogram of IDO expressions: $24 \%$ had low IDO expression, $27 \%$ had medium IDO expression, and $49 \%$ had high IDO expression. Abbreviation: IDO, indoleamine 2,3 dioxygenase.

and tumor ER (OR, 1.12; 95\% CI, 0.30-4.16, $P=0.86$ ), PR (OR, 2.57; 95\% CI, 0.69-9.59, $P=0.16$ ), and HER2-neu (OR, 2.83; 95\% CI, 0.73-10.92, $P=0.12$ ) status. TNBC patients were associated with higher IDO expression 

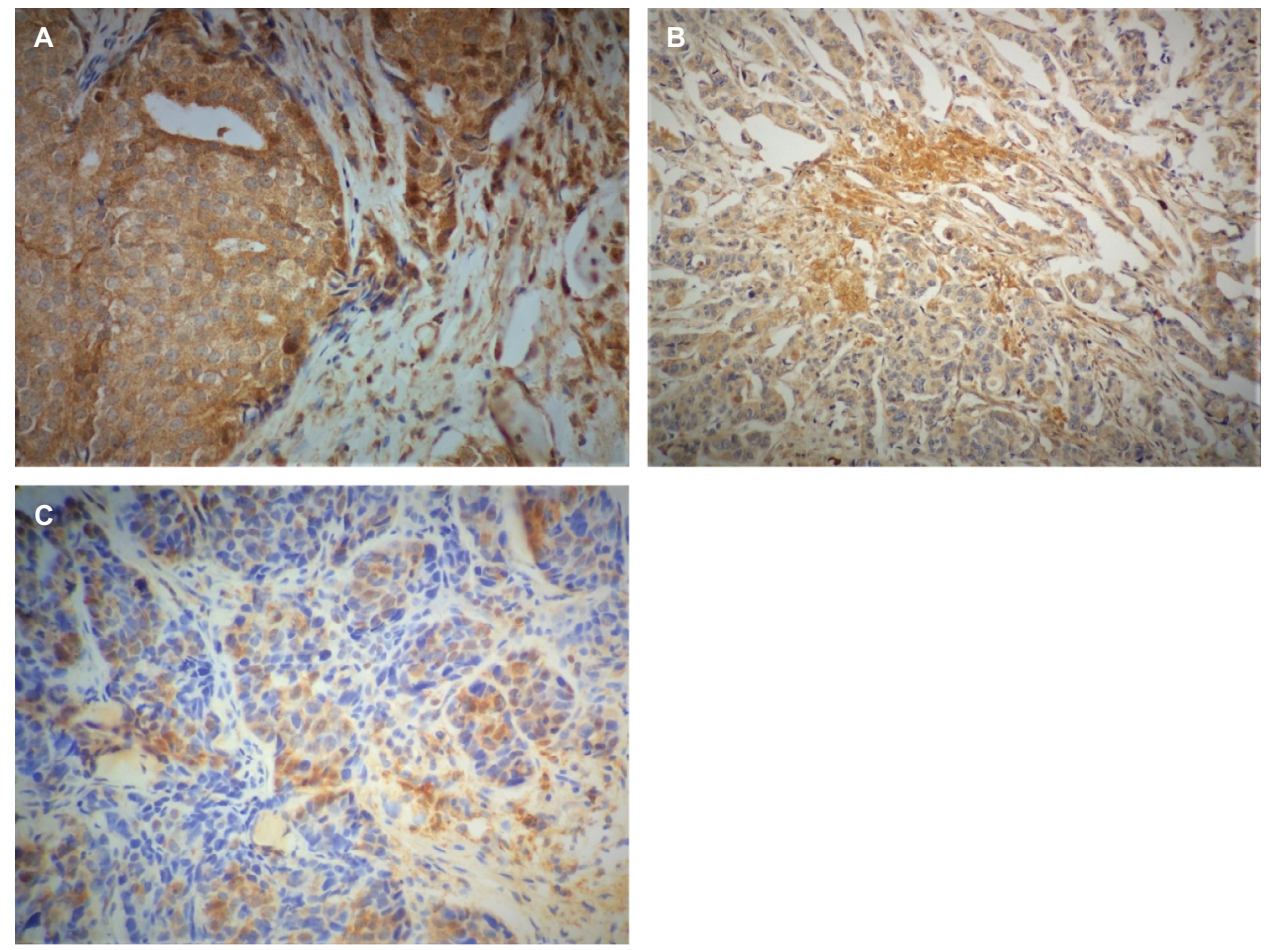

Figure 3 IDO immunostaining images.

Notes: IDO protein expression in breast cancer tissue $(n=100)$ was evaluated by immunohistochemistry. Formalin-fixed paraffin-embedded sections were stained using mouse monoclonal antibody against human IDO. (A) Strong and diffuse IDO staining was observed in malignant ductal tumor cells. (B) Moderate IDO-positive staining was detected in invasive ductal tumor cells. (C) Weak IDO staining was observed in the breast tumor cell. Images were captured at $40 \times$ magnification.

Abbreviation: IDO, indoleamine 2,3 dioxygenase.

Table 2 Univariable and multivariable ordinal regression for IDO scores - low (reference) vs medium and high

\begin{tabular}{|l|l|l|l|}
\hline Variables & Characteristics & $\begin{array}{l}\text { Univariable analysis, } \\
\text { OR (95\% CI), P-value }\end{array}$ & $\begin{array}{l}\text { Multivariable analysis, } \\
\text { OR (95\% CI), P-value }\end{array}$ \\
\hline Estrogen receptor & Negative & Reference & $\begin{array}{l}\text { Reference } \\
\text { Positive }\end{array}$ \\
& Negative & $0.53(0.24-1.60), 0.1 I$ & Reference \\
\hline Progesterone receptor & Positive & Reference & $2.57(0.69-9.59), 0.16$ \\
\hline & Negative & $0.7 I(0.31-1.6 I), 0.4 I$ & Reference \\
\hline HER2-neu receptor & Positive & Reference & $2.83(0.73-10.92), 0.12$ \\
\hline Triple-negative breast cancer & No & $0.73(0.32-1.68), 0.50$ & Reference \\
\hline & Yes & Reference & $8.04(1.70-39.02), 0.0 I^{\mathrm{a}}$ \\
\hline
\end{tabular}

Note: aStatistical significance: $P<0.05$.

Abbreviations: HER2, human EGF receptor 2; IDO, indoleamine 2,3 dioxygenase.

compared to the non-TNBC patients (OR, 8.04; 95\% CI, $1.70-39.02, P=0.01$ ).

\section{Discussion}

It has been documented that IDO emerged from tumors has ability to constrain the immune responses against tumor. ${ }^{23}$ IDO is suggested to play a pivotal role in the pathogenesis of breast cancer. To the best of our knowledge, this is the first study that establishes the expression of IDO in Pakistani breast cancer patients. The findings of current study support the observation that increased IDO expression $(P=0.01)$ is associated with TNBC patients (65.3\%) compared to the non-
TNBC patients (33.3\%), coherent with the finding published by Kim et $\mathrm{al}^{23}$ and Dill et al. ${ }^{24}$ Jaquemiere et a ${ }^{21}$ also observed high IDO expression in basal-like breast carcinoma (BLBC), a subtype of TNBC. They mainly investigated IDO expression at mRNA level; however, we investigated IDO protein expression in tissues. IDO expression at transcriptional level can be different from IDO expression at translational level due to various factors. Therefore, we presume that IDO expression at protein level may act as a more consistent factor to investigate. Soliman et $\mathrm{a}^{25}$ revealed that IDO expression was higher in $\mathrm{ER}^{+}$tumor in comparison with $\mathrm{ER}^{-}$tumors $(P=0.0064)$. In our study, we could not find an association 
between IDO expression and HER2, PR, or ER status in breast cancer patients, which was primarily consistent with the recently published study by Wei et al. ${ }^{26}$

IDO overexpression is associated with shorter overall survival in patients with solid tumors. ${ }^{12-14,27-31}$ Soliman et $\mathrm{al}^{25}$ validated that high IDO expression is associated with better survival outcomes in breast cancer patients, consistent with findings presented by Jaquemiere et al. ${ }^{21}$ In our study, overall survival data were compared among the IDO high, IDO medium, and IDO low groups. There was a statistically significant difference $(P=0.04)$ between the three groups. Our data confirmed that high IDO expression is associated with the poor prognosis of the patients. This is similar to the findings by Wei et al. ${ }^{26}$

IDO expression has immunological and non-immunological effects on breast tumor growth. ${ }^{32}$ It is imperative to understand the involvement of IDO in the progression of breast cancer. ${ }^{25}$ IDO has a potential to be used as an immunotherapeutic target in TNBC patients. ${ }^{33}$ This study had some limitations. This study was conducted on 100 patients. Future studies on Pakistani breast cancer patients with a broader cohort are warranted to establish definitive correlations.

IDO is not expressed in normal breast tissues. ${ }^{34}$ Our data suggest that IDO expression was higher in the TNBC patients compared to that in the non-TNBC patients. Furthermore, high IDO expression is considerably linked with overall decreased patient survival and poor prognosis in patients diagnosed breast cancer in Pakistan. Tumors with increased IDO expression and decreased patients' survival endorse the idea that a treatment modality involving IDO inhibition may have antitumor effects. Thus, IDO is a promising target for therapeutic intervention specifically in TNBC patients.

\section{Acknowledgments}

This study was supported by Shaukat Khanum Memorial Cancer Hospital and Research Centre (SKMCH \& RC), Lahore, Pakistan. We are grateful to the study co-investigators for their input. Development of this manuscript has been supported by SKMCH \& RC (Institute Award no: IRB-16-08).

\section{Disclosure}

This manuscript is the first study conducted in Pakistan according to the best of our knowledge, and it was never presented or published in any national or international conference or journal. The authors report no conflicts of interest in this work.

\section{References}

1. Mansfield AS, Heikkila PS, Vaara AT, von Smitten KA, Vakkila JM, Leidenius MH. Simultaneous Foxp3 and IDO expression is associated with sentinel lymph node metastases in breast cancer. BMC Cancer. 2009;9:231.

2. Muller AJ, Duhadaway JB, Donover PS, Sutanto-Ward E, Prendergast GC. Inhibition of indoleamine 2,3-dioxygenase, an immunoregulatory target of the cancer suppression gene Bin1, potentiates cancer chemotherapy. Nat Med. 2005;11(3):312-319.

3. Lee GK, Park HJ, Macleod M, Chandler P, Munn DH, Mellor AL. Tryptophan deprivation sensitizes activated $\mathrm{T}$ cells to apoptosis prior to cell division. Immunology. 2002;107(4):452-460.

4. Munn DH, Shafizadeh E, Attwood JT, Bondarev I, Pashine A, Mellor AL. Inhibition of T cell proliferation by macrophage tryptophan catabolism. J Exp Med. 1999;189(9):1363-1372.

5. Mellor AL, Munn DH. Tryptophan catabolism and T-cell tolerance: immunosuppression by starvation? Immunol Today. 1999;20(10):469-473.

6. Mellor AL, Munn DH. IDO expression by dendritic cells: tolerance and tryptophan catabolism. Nat Rev Immunol. 2004;4(10):762-774.

7. Grohmann U, Fallarino F, Puccetti P. Tolerance, DCs and tryptophan: much ado about IDO. Trends Immunol. 2003;24(5):242-248.

8. Katz JB, Muller AJ, Prendergast GC. Indoleamine 2,3-dioxygenase in T-cell tolerance and tumoral immune escape. Immunol Rev. 2008;222:206-221.

9. Schröcksnadel K, Wirleitner B, Winkler C, Fuchs D. Monitoring tryptophan metabolism in chronic immune activation. Clin Chim Acta. 2006;364(1-2):82-90.

10. Nakamura T, Shima T, Saeki A, et al. Expression of indoleamine 2, 3-dioxygenase and the recruitment of Foxp3-expressing regulatory $\mathrm{T}$ cells in the development and progression of uterine cervical cancer. Cancer Sci. 2007;98(6):874-881.

11. Yu J, Du W, Yan F, et al. Myeloid-derived suppressor cells suppress antitumor immune responses through IDO expression and correlate with lymph node metastasis in patients with breast cancer. J Immunol. 2013;190(7):3783-3797.

12. Brandacher G, Perathoner A, Ladurner R, et al. Prognostic value of indoleamine 2,3-dioxygenase expression in colorectal cancer: effect on tumor-infiltrating T cells. Clin Cancer Res. 2006;12(4): 1144-1151.

13. Okamoto A, Nikaido T, Ochiai K, et al. Indoleamine 2,3-dioxygenase serves as a marker of poor prognosis in gene expression profiles of serous ovarian cancer cells. Clin Cancer Res. 2005;11(16): 6030-6039.

14. Ino K, Yoshida N, Kajiyama H, et al. Indoleamine 2,3-dioxygenase is a novel prognostic indicator for endometrial cancer. $\mathrm{Br} J$ Cancer. 2006;95(11):1555-1561.

15. Moon YW, Hajjar J, Hwu P, Naing A. Targeting the indoleamine 2,3-dioxygenase pathway in cancer. J Immunother Cancer. 2015;3(1):51.

16. International Agency for Research on Cancer [webpage on the Internet]. Estimated Incidence, Mortality and Prevalence Worldwide in 2012. IARC; 2012. Available from: http://globocan.iarc.fr/Pages/ fact_sheets_cancer.aspx. Accessed April 18, 2018.

17. Yu J, Sun J, Wang SE, et al. Upregulated expression of indoleamine 2, 3-dioxygenase in primary breast cancer correlates with increase of infiltrated regulatory T cells in situ and lymph node metastasis. Clin Dev Immunol. 2011;2011(2):1-10.

18. Curigliano G, Goldhirsch A. The triple-negative subtype: new ideas for the poorest prognosis breast cancer. $J$ Natl Cancer Inst Monogr. 2011;2011(43):108-110.

19. Penault-Llorca F, Viale G. Pathological and molecular diagnosis of triple-negative breast cancer: a clinical perspective. Ann Oncol. 2012;23(Suppl 6):vi19-vi22.

20. Jamdade VS, Sethi N, Mundhe NA, Kumar P, Lahkar M, Sinha N. Therapeutic targets of triple-negative breast cancer: a review. $\mathrm{Br} J$ Pharmacol. 2015;172(17):4228-4237. 
21. Jacquemier J, Bertucci F, Finetti P, et al. High expression of indoleamine 2,3-dioxygenase in the tumour is associated with medullary features and favourable outcome in basal-like breast carcinoma. Int J Cancer. 2012;130(1):96-104.

22. Chen X, Cho DB, Yang PC. Double staining immunohistochemistry. $N$ Am J Med Sci. 2010;2(5):241-245.

23. Kim S, Park S, Cho MS, Lim W, Moon BI, Sung SH. Strong correlation of indoleamine 2,3-Dioxygenase 1 expression with basal-like phenotype and increased lymphocytic infiltration in triple-negative breast cancer. J Cancer. 2017;8(1):124-130.

24. Dill EA, Dillon PM, Bullock TN, Mills AM. IDO expression in breast cancer: an assessment of 281 primary and metastatic cases with comparison to PD-L1. Mod Pathol. 2018;31(10):1513-1522.

25. Soliman H, Rawal B, Fulp J, et al. Analysis of indoleamine 2-3 dioxygenase (IDO1) expression in breast cancer tissue by immunohistochemistry. Cancer Immunol Immunother. 2013;62(5):829-837.

26. Wei L, Zhu S, Li M, et al. High indoleamine 2,3-Dioxygenase is correlated with microvessel density and worse prognosis in breast cancer. Front Immunol. 2018;9:724.

27. Huang A, Fuchs D, Widner B, Glover C, Henderson DC, Allen-Mersh TG. Serum tryptophan decrease correlates with immune activation and impaired quality of life in colorectal cancer. Br J Cancer. 2002;86(11): 1691-1696.
28. Ino $\mathrm{K}$, Yamamoto $\mathrm{E}$, Shibata $\mathrm{K}$, et al. Inverse correlation between tumoral indoleamine 2,3-dioxygenase expression and tumor-infiltrating lymphocytes in endometrial cancer: its association with disease progression and survival. Clin Cancer Res. 2008;14(8):2310-2317.

29. Astigiano S, Morandi B, Costa R, et al. Eosinophil granulocytes account for indoleamine 2,3-dioxygenase-mediated immune escape in human non-small cell lung cancer. Neoplasia. 2005;7(4):390-396.

30. Weinlich G, Murr C, Richardsen L, Winkler C, Fuchs D. Decreased serum tryptophan concentration predicts poor prognosis in malignant melanoma patients. Dermatology. 2007;214(1):8-14.

31. Takao M, Okamoto A, Nikaido T, et al. Increased synthesis of indoleamine-2,3-dioxygenase protein is positively associated with impaired survival in patients with serous-type, but not with other types of, ovarian cancer. Oncol Rep. 2007;17(6):1333-1339.

32. Levina V, Su Y, Gorelik E. Immunological and nonimmunological effects of indoleamine 2,3-dioxygenase on breast tumor growth and spontaneous metastasis formation. Clin Dev Immunol. 2012;2012(12):1-12.

33. Noonepalle SK, Gu F, Lee EJ, et al. Promoter methylation modulates indoleamine 2,3-dioxygenase 1 induction by activated T cells in human breast cancers. Cancer Immunol Res. 2017;5(4):330-344.

34. Théate I, van Baren N, Pilotte L, et al. Extensive profiling of the expression of the indoleamine 2,3-dioxygenase 1 protein in normal and tumoral human tissues. Cancer Immunol Res. 2015;3(2):161-172.
Cancer Management and Research

\section{Publish your work in this journal}

Cancer Management and Research is an international, peer-reviewed open access journal focusing on cancer research and the optimal use of preventative and integrated treatment interventions to achieve improved outcomes, enhanced survival and quality of life for the cancer patient. The manuscript management system is completely online and includes

\section{Dovepress}

a very quick and fair peer-review system, which is all easy to use. Visit http://www.dovepress.com/testimonials.php to read real quotes from published authors. 